\title{
Original Article (short paper) \\ Resistance training and hormone replacement increase MMP-2 activity, quality and quantity of bone in ovariectomized rats
}

\author{
Markus V.C Souza ${ }^{1 *}$, Anderson D. S Lino ${ }^{2}$, Leandro G. D Ruffoni ${ }^{2}$, Mateus M. Domingos ${ }^{2,3}$, Marina R. Barbosa ${ }^{2,4}$, \\ Maria F C. Rodrigues ${ }^{2}$, Fabiano C. Ferreira ${ }^{2}$, Luciane M. Tomaz², Gustavo H. R. Canevazzi², Natália S. Silva ${ }^{2}$, Jefer- \\ son A. A. Teixeira ${ }^{2}$, Richard D. Leite ${ }^{5}$, Gilberto E. Shiguemoto ${ }^{2}$, Sérgio E. A. Perez ${ }^{2}$ \\ ${ }^{1}$ Universidade Federal do Triângulo Mineiro, UFTM, Uberaba, MG, Brazil; ${ }^{2}$ Universidade Federal de São Carlos, UFSCar, São \\ Carlos, SP, Brazil; ${ }^{3}$ Centro Universitário das Faculdades Associadas de Ensino, FAE, São João da Boa Vista,SP, Brazil, ${ }^{4}$ Uni- \\ versidade Federal do Sergipe, UFS, Aracaju, SE, Brazil; ${ }^{5}$ Universidade Federal do Espírito Santo, UFES, Vitória, ES, Brazil.
}

\begin{abstract}
Aims: The aim of the present study was to investigate the influence of resistance training (RT) and hormone replacement (HR) on MMP-2 activity, biomechanical and physical properties bone of ovariectomized (OVX) rats. Methods: Sprague-Dawley female rats were grouped into six experimental groups $(\mathrm{n}=11$ per group): sham-operated sedentary (SHAM Sed), ovariectomized sedentary (OVX Sed), sham-operated resistance training (SHAM RT), ovariectomized resistance training (OVX RT), ovariectomized sedentary hormone replacement (OVX Sed-HR), and ovariectomized resistance training hormone replacement (OVX RT-HR). HR groups received implanted silastic capsules with a $5 \%$ solution of $17 \beta$-estradiol (50 mg $17 \beta$-estradiol $/ \mathrm{ml}$ of sunflower oil). In a 12-week RT period ( $27 \mathrm{sessions}$; 4-9 climbs) the animals climbed a $1.1 \mathrm{~m}$ vertical ladder with weights attached to their tails. Biomechanical and physical bone analyses were performed using a universal testing machine, and MMP-2 activity analysis was done by zymography Results: Bone density and bone mineral content was higher in the RT and HR groups. The MMP-2 activity was higher in the RT and HR groups. The biomechanical analysis (stiffness, fracture load and maximum load) demonstrated better bone tissue quality in the RT associated with HR. Conclusion: The RT alone as well as when it is associated with HR was efficient in increasing MMP-2 activity, biomechanical and biophysical properties bone of ovariectomized rats.
\end{abstract}

Keywords: osteoporosis, resistance training, ovariectomy, hormone replacement and metalloproteinase-2 (MMP-2).

\section{Introduction}

Osteoporosis is one of the most serious health problems of postmenopausal women, and occurs in approximately $20 \%$ of them $^{1}$. Estrogen deficiency is related with decline in bone mass and disruption of the micro architectural arrangement of bone tissue. Previous studies show that the ovariectomy results in an increased bone turnover with osteoclastic resorption exceeding the osteoblastic formation ${ }^{2-4}$. This condition contributes to increased urinary calcium excretion ${ }^{5,6}$, bone mineral content and bone density reduction, loss in mechanical strength and increased fracture risk. Bone quality is influenced by many factors, such as alterations on extracellular matrix (ECM), modifications at organic composition (collagen and non-collagenous matrix proteins), inorganic composition (hydroxyapatite) and activity of matrix metalloproteinases (MMPs) ${ }^{3}$.

Matrix metalloproteinases (MMPs) are responsible for the breadown of ECM components that contributes to normal tissue regulation and remodeling and the matrix metalloproteinases 2 (MMP-2), which are important for the integrity of the ECM at the bone ${ }^{3,7}$. The increase of MMP-2 activity is indicative of matrix degradation, a process necessary for tissue growth ${ }^{3}$. Previous studies showed that the reduction in MMP-2 causes destruction of bone tissue favoring osteoporosis; this fact demonstrated the importance of MMP-2 in the development and maintenance of bone tissue $\mathrm{e}^{3,8}$.

Ovariectomy is associated with a reduction in the production of the ovarian hormones, which decreases the activity of
MMP-2 ${ }^{9-11}$. The reduction of these hormones causes many effects on the body, including the increase in body fat ${ }^{10,12}$, which favors the concentrations of circulating inflammatory markers such as tumor necrosis factor alpha (TNF- $\alpha$ ) and interleukin 1 and $6^{13,14}$. These markers increase the activity of MMP- $2^{14}$, and increase bone remodeling. This physiological change causes changes in the morphology and function of the bones, which negatively affect the skeleton ${ }^{14}$.

The bone demineralization and collagen decrease are associated with the higher osteoclastic activity in the absence of estrogen, thereby promoting reduction in the biophysical and biomechanical properties of bones ${ }^{3}$. Thus, the hormone replacement therapy is considered to minimize the ovariectomy effects ${ }^{10}$.

Hormone replacement promotes tissue remodeling, favoring the biomarkers' activation that reflect the: 1) bone resorption; 2) number of osteoclasts, and 3) bone formation. Markers of bone formation are divided into two categories: 1) increased proteins that induces the osteoblast differentiation, and 2) pro collagen fragments that are released during incorporation of collagen in the bone matrix ${ }^{1}$. Thus, the development of pharmacological and non-pharmacological therapies is needed to reduce the effects caused by the absence of ovarian hormones.

Exercise has generally been considered to have positive influence on the skeleton with mechanical loading being the main exercise modalities to preserve and improve bone mass and strength ${ }^{3,15}$. Several exercise modalities including treadmill ${ }^{16}$, jump ${ }^{11}$, whole body vibration ${ }^{17}$, resistance training on the stairs ${ }^{3}$ and swimming ${ }^{18}$ were studied on bone loss in osteoporosis rat models. 
The RT has been used to promote positive changes in body composition such as lower body mass and fat mass and higher lean mass ${ }^{3,19,20}$. However, the direct effect of RT plus HR on MMP-2 activity and quality bone tissue remain unclear. A better understanding of MMP-2 activity could elucidate the physiological responses in bone development and maintenance. Therefore, the aim of this study was to determine the effect of resistance training, whether associated or not, with Hormone Replacement (HR) in the MMP-2 activity and bone tissue quality in ovariectomized rats. Our hypothesis is that RT, HR and the association of both interventions are efficient in increasing the quality and quantity of bone tissue.

\section{Methods}

\section{Animals}

Sixty-six Holstman adult female rats were used from the animal facility of the University of São Paulo State (UNESP, Araraquara, Brazil), with body weight of approximately $220 \pm 12 \mathrm{~g}$. The animals had free access to water and chow, and were kept in collective cages ( 3 rats per cage) at a constant temperature of $22 \pm 20 \mathrm{C}$, and had a $12 \mathrm{~h} \mathrm{light} / 12 \mathrm{~h}$ dark cycle, with light from $1 \mathrm{a}$.m. All animals remained in the acclimatization process to the animal house and light/dark cycle for three weeks, until reach $240-250 \mathrm{~g}$ to start the experimental procedures before to separate the experimental groups and start of experimental protocol. All animal procedures were conducted in accordance with the guide for the care and use of laboratory animals (National Research Council, 1998) and the Federal University of São Carlos (UFSCar). The Committee of Experimental Animals (protocol no. 005/2013) approved the protocol.

\section{Experimental groups}

The rats were randomly divided into the following six experimental groups (eleven animals per group): sham-operated sedentary (SHAM Sed), ovariectomized sedentary (OVX Sed), sham-operated resistance training (SHAM RT), ovariectomized resistance training (OVX RT), ovariectomized sedentary hormone replacement (OVX Sed-HR), and ovariectomized resistance training hormone replacement (OVX RT-HR).

The sedentary animals (SHAM Sed, OVX Sed, and OVX Sed-HR) were maintained in their cages over the whole experimental period without any type of training. The OVX animals (OVX Sed, OVX RT, OVX Sed-HR, and OVX RT-HR) had their ovaries removed. The trained animals (SHAM RT, OVX RT and OVX RT-HR) performed 12 weeks of resistance training. The training started at the same time for each group.

\section{Ovariectomy and sham operation}

Ovariectomy and sham operations were performed when the rats reached 250 grams of body weight, according to the technique described by $\mathrm{Kalu}^{21}$. For the surgery, rats were anesthetized with a mixture of ketamine-xylazine $(61.5-7.6 \mathrm{mg} / \mathrm{kg}$, intraperitoneally). The sham-operated rats underwent the surgical procedure but did not have their ovaries removed. The OVX animals had their ovaries removed. All animals who underwent surgical procedures had one week of recovery. All animals had the same exposure time to the surgical procedures until the date of sacrifice.

\section{Resistance exercise training}

During the 12-week resistance training, climbing sessions were performed once every 3 days. Initially, the rats adapted to the resistance training protocol, which required that the animals climb a vertical ladder ( $1.1 \mathrm{~m} \times 0.18 \mathrm{~m} \mathrm{x} 2 \mathrm{~cm}$ grid, $80^{\circ}$ incline) with weights attached to their tails. The length of the ladder induced the animals to perform 8-12 movements per climb. The load apparatus was attached to the tail by wrapping the proximal portion of the tail.

At the top of the ladder, the rats reached a housing chamber $(20 \mathrm{~cm} \times 20 \mathrm{~cm} \times 20 \mathrm{~cm})$, where they were allowed to rest for $120 \mathrm{~s}$. This procedure was repeated until the rats would voluntarily climb the ladder for 3 consecutive times, without stimulus.

The determination of the loading charge is of 4-9 ladder climbs while carrying progressively heavier loads. The initial climb consisted of carrying a load that was $75 \%$ of the animal's body weight. A series of additional $30 \mathrm{~g}$ weights were added until the load hampered the animal's capacity to climb the entire ladder. Failure was established after three non-successful attempts to reach the top of the ladder. The highest load successfully carried over the entire length of the ladder was considered the rat's maximal carrying load (MCL) for that training session.

The next training sessions consisted of 4 ladder climbs with $50 \%, 75 \%, 90 \%$, and $100 \%$ of the rat's previous MCL, determined in the previous session. During subsequent ladder climbs, an additional $30 \mathrm{~g}$ load was added for up to five attempts until a new MCL was determined. The resistance training protocol was adapted from Hornberger and Farrar ${ }^{22}$, according to the needs of the current research, and was already done by our group ${ }^{3,9,11,20,23}$.

\section{Hormone replacement $(H R)$}

The animals in hormone replacement groups (OVX Sed-HR and OVX RT-HR) received subcutaneously implanted silastic capsules according to the technique described by Ingberg, Theodorsson (24). Therapy was performed by means of Silastic $\AA$ Capsules (Dow Corning, VWR International, Buffalo Grove, IL, USA). The capsules were of $15 \mathrm{~mm}$ length and had an internal diameter of $1.02 \mathrm{~mm}$, with a $5 \%$ solution of $17 \beta$-estradiol (50 $\mathrm{mg} 17 \beta$-estradiol $/ \mathrm{ml}$ of sunflower oil). The volume of the solution administered to each capsule was $10 \mu \mathrm{L}$. After addition, the capsules were sealed on both sides with adhesive Silastic $\AA$. The capsules were stored dry for 24 hours for the drying of the glue. After drying, they were kept in a saline solution $(0.9 \%$ saline) for at east 2 hours. The vehicle used in the capsules of the hormone replacement and placebo groups was sunflower oil. 


\section{Euthanasia and Tissue sampling}

Animals were euthanized by decapitation $48 \mathrm{~h}$ after the last training session to minimize any potentially confounding effects of the last bout of exercise on the outcome measures. Sedentary animals were also euthanized at the same period.

Bones were frozen in liquid nitrogen and stored at $-84^{\circ} \mathrm{C}$ for biochemical and biomechanical analyses. The right tibia was utilized for MMP-2 activity analysis, and the left tibia for physical and biomechanical properties' analyses of bone tissue.

\section{MMP-2 activity analysis}

The techniques for bone MMP-2 activity determination were performed according to the protocol established by Marqueti, Prestes $^{11}$, which was adapted for this study. Each group of rats was analyzed separately. The proximal third was removed and macerated with liquid nitrogen. The macerated bone sample was incubated in a $2 \mathrm{~mL}$ extraction buffer $[10 \mathrm{mM}$ cacodylic acid, pH $5.0 ; 0.15 \mathrm{M} \mathrm{NaCl} ; 1 \mathrm{M} \mathrm{ZnCl}_{2} ; 20 \mathrm{mM} \mathrm{CaCl}_{2} ; 1.5 \mathrm{mM} \mathrm{NaN}_{3}$; $0.01 \%$ Triton $\mathrm{X}-100(\mathrm{v} / \mathrm{v})]$ at $4^{\circ} \mathrm{C}$ overnight with continuous stirring. After this period, the solution was centrifuged for $20 \mathrm{~min}$ $\left(13.000 \mathrm{~g}\right.$ at $\left.4^{\circ} \mathrm{C}\right)$. Samples applied $40 \mathrm{mg}$ of the total protein in each lane of sodium dodecyl sulfate (SDS) $10 \%$ polyacrylamide gels prepared with $1 \mathrm{mg} / \mathrm{mL}$ gelatin. After electrophoresis, the gels were washed twice in $2.5 \%$ Triton X-100 to remove SDS. Gels were incubated in buffer substrate $(50 \mathrm{mM}$ Tris-HCl, $\mathrm{pH}$ $8.0 ; 5 \mathrm{mM} \mathrm{CaCl}_{2} ; 0.02 \% \mathrm{NaN}_{3}$ ) at $37^{\circ} \mathrm{C}$ for $20 \mathrm{~h}$. Gels were stained with Comassie brilliant blue for $1 \mathrm{~h}$ and destained with acetic acid:methanol:water (1:4:5) for visualization of the activity bands. The gels were photographed using a Canon G6 Power Shot 7.1 mega pixel camera (Newport News, Virginia, USA). The averages of the band intensities were measured using the Gene Tools software (Philomath, Oregon, USA). The bands found in all groups were of 72-62 kDa, suggesting the activation of MMP-2.

\section{Biometric analysis}

The body weights of rats were measured before training sessions in a precision digital weighing machine (KERN, model 573, Balingen, Germany) for longitudinal follow-up. Left tibia length measurements were performed using a caliper rule (precision of $0.05 \mathrm{~mm}$ ), taking as references the tibial plateau and the medial malleolus.

\section{Biomechanical analysis}

After biometric analysis, the bones were kept in a desiccator for $24 \mathrm{~h}$ so as to remove the air present in the bone pores. After this, the immersed mass $(M \quad)$ and wet mass $(\mathrm{m} \quad$ ) were obtained; then, biomechanical analysis was started. The biomechanical properties were measured by the three-point bending test using a universal test machine (Instron, model 4444, Canton, Massachusetts, USA) and a load cell with a capacity of 100 kgf. Bones' extremities were supported on two rollers with 3 $\mathrm{mm}$ diameter, and at a distance of $21.70 \mathrm{~mm}$. Load was applied in the central region of each bone in accordance with Trebacz and Zdunek ${ }^{25}$. At the beginning of the test, a $10 \mathrm{~N}$ pre-load was applied in the posterior-anterior direction (perpendicular to the longitudinal axis) to establish the tibia. After a $1 \mathrm{~min}$ accommodation and stabilization period, a force was applied in the same way at a constant velocity of $0.5 \mathrm{~cm} / \mathrm{min}$ up to the fracture moment. As a result of the force applied to the tibia, the Instron software (series IX) generated a graphic load strain; in this graphic, the main biomechanical properties that were obtained were maximum force $(\mathrm{N})$, rupture force $(\mathrm{N})$ and stiffness $(\mathrm{N} / \mathrm{mm})$.

\section{Biochemical analysis}

After obtaining the right femurs of mineral material, solubilization was performed in $2 \mathrm{~N}$ hydrochloric acid. Subsequently, using a colorimetric assay, the content of calcium and phosphorus from bones were determined using the commercial kit specific Labtest ${ }^{\circledR}$.

\section{Densitometry}

After biomechanical analysis of bone mineral density (BMD, $\mathrm{g} / \mathrm{cm} 2)$ and bone mineral content (BMC, $\mathrm{g}$ ) and area $(\mathrm{cm} 2)$, these were assessed using densitometer model DPX-ALPHA, with a special software for small animals (Faculty of Veterinary Medicine Araçatuba/UNESP, Araçatuba, SP).

Calculation of bone mineral density: $\mathrm{BMD}=\underline{\mathrm{BMC}}$

$\overline{\text { AREA }}$

\section{Statistical analysis}

All data were presented as mean \pm standard deviation of the mean (SDM). Initially, the statistical analysis was done both by Kolmogorov-Smirnov normality test and homocedasticity test. All variables presented normal distribution and homocedasticity, so, the two-way ANOVA test was used to compare the variables of resistance training, hormone replacement and ovariectomy. Fisher's post hoc test was used in the event of a significant ratio $(\mathrm{p}<0.05)$. All statistical procedures were performed by SPSS statistics (version 20).

\section{Results}

No statistical differences were observed between all experimental groups for initial body weight. The OVX Sed, OVX Sed-HR and OVX RT groups presented the final body weight as being significantly higher compared to SHAM Sed and SHAM RT groups $(P$ $<0.05$; table 1$)$. There is no statistical difference between OVX RT-HR and SHAM groups (Sed and RT). The OVX Sed group 
presented a significantly higher regular food consumption and uterus weight $(P<0.05$; table 1$)$ compared to all experimental groups. Thus, we observed a higher tibia weight in OVX RT-HR compared to SHAM Sed and OVX Sed $(P<0.05$; table1).

Table 1: Body weight, Food intake, Uterus weight, Tibia weight and Tibia length.

\begin{tabular}{|c|c|c|c|c|c|c|}
\hline \multirow{3}{*}{ Variables } & \multicolumn{6}{|c|}{ Experimental Groups } \\
\hline & \multicolumn{2}{|c|}{ Sham Groups } & \multicolumn{4}{|c|}{ Ovariectomy Groups } \\
\hline & Sed & RT & Sed & RT & Sed-HR & RT-HR \\
\hline Body Weight Initial (g) & $246.8 \pm 12.3$ & $250.1 \pm 13.8$ & $240.2 \pm 14.6$ & $245.3 \pm 15.4$ & $247.1 \pm 15.6$ & $251.5 \pm 16.0$ \\
\hline Body Weight Final (g) & $305.6 \pm 18.6^{\mathrm{a}}$ & $317.4 \pm 12.9^{\mathrm{a}}$ & $358.9 \pm 33.5^{\mathrm{ab}}$ & $346.2 \pm 23.0^{\mathrm{abcd}}$ & $306.5 \pm 30.2^{\mathrm{abcd}}$ & $316.1 \pm 30.2^{\text {ade }}$ \\
\hline Food intake (g/d) & $21.0 \pm 0.5$ & $22.7 \pm 0.5$ & $23.3 \pm 0.9^{b}$ & $23.2 \pm 0.6^{\mathrm{b}}$ & $22.2 \pm 0.8$ & $22.5 \pm 0.7$ \\
\hline Uterus weight (g) & $0.67 \pm 0.0$ & $0.63 \pm 0.0$ & $0.11 \pm 0.0^{\mathrm{bc}}$ & $0.09 \pm 0.0^{\mathrm{bc}}$ & $0.64 \pm 0.0^{\mathrm{de}}$ & $0.62 \pm 0.0^{\mathrm{de}}$ \\
\hline Tibia weight (g) & $0.57 \pm 0.0$ & $0.66 \pm 0.0$ & $0.61 \pm 0.0^{\mathrm{bc}}$ & $0.65 \pm 0.0^{\mathrm{b}}$ & $0.60 \pm 0.0$ & $0.61 \pm 0.0^{\text {bd }}$ \\
\hline Tibia length (mm) & $4.02 \pm 0.1$ & $4.06 \pm 0.0$ & $4.13 \pm 0.0$ & $4.11 \pm 0.0$ & $3.97 \pm 0.0$ & $3.98 \pm 0.0$ \\
\hline
\end{tabular}

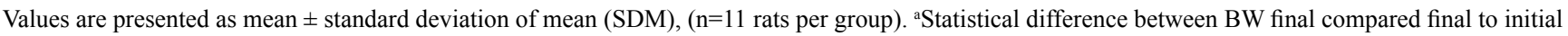
moments of experiments for the same group $(\mathrm{P}<0.05)$. ${ }^{\mathrm{b}}$, Statistical difference from Sham-Sed: $(\mathrm{P}<0.05)$. $^{\mathrm{c}}$, Statistical difference from Sham-RT: $(\mathrm{P}<0.05)$. ${ }^{\mathrm{e}}$, Statistical difference from Ovx-Sed: $(\mathrm{P}<0.05)$. ${ }^{\mathrm{e}}$, Statistical difference from Ovx-RT $(\mathrm{P}<0.05)$.

The trained groups demonstrate a significantly progressive increases in the workload after session 1, 13 and 27 . Significantly higher workload was observed when compared to session 27 $(P<0.05$; Table 2).

Table 2: Maximal workload $(\mathrm{g})$

\begin{tabular}{cccc}
\hline Groups & RT Session 1 & RT Session 13 & RT Session 27 \\
\hline SHAM RT & $370.5 \pm 43.7$ & $755.09 \pm 100.32^{\mathrm{a}}$ & $962.3 \pm 92.05^{\mathrm{bc}}$ \\
OVX RT & $334.3 \pm 57.1$ & $762.5 \pm 84.4^{\mathrm{a}}$ & $926.1 \pm 78.2^{\mathrm{b}}$ \\
OVX RT-HR & $350.0 \pm 44.3$ & $750.9 \pm 96.5^{\mathrm{a}}$ & $971.8 \pm 111.1^{\mathrm{bc}}$ \\
\hline
\end{tabular}

Values are presented as mean \pm standard deviation of mean $(\mathrm{SDM}),(\mathrm{n}=11$ rats per group). $\mathrm{RT}$ indicates Resistance Training. aStatistically difference from RT Session $1(\mathrm{P}<0.05)$. bStatistical difference from RT Session 1 and $13(\mathrm{P}<0.05)$. cStatistical difference from OVX RT $(\mathrm{P}<0.05)$.

Fig 1 shows the physical analysis results for bone density (BD), bone mineral content (BMC), and area. Bone density and bone mineral content (Fig 1A-B) was significantly higher in trained groups (OVX RT and OVX RT-HR) compared to groups without training $(P<0.05)$. The hormone replacement was able to increase the BD, BMC, and area in the OVX Sed-HR and OVX RT-HR groups. Moreover, we observed significantly higher values of BD, BMC and area in the OVX Sed-HR when compared to the OVX Sed group $(P<0.05)$. The association between HR and RT (OVX RT-HR) induced higher values of BD, BMC and area (Figure 1). However, when hormone replacement was associated with training, these values were significantly different from other ovariectomized groups $(P<0.05)$.

The RT was able to increase the calcium and phosphorus concentrations in bones. The comparison between SHAM Sed and SHAM RT demonstrate that resistance training induced significantly higher calcium and phosphorus concentration $(P<0.05$; Fig 2$)$. On the other hand, ovariectomy reduced markedly the calcium and phosphorus concentrations; this is seen when comparing OVX Sed with SHAM Sed $(P<0.05)$.
RT, HR and the association were able to increase significantly, the concentration of calcium and phosphorus in the bones of ovariectomized rats $(P<0.05)$. No statiscally difference was observed when comparing OVX RT, OVX Sed-HR and OVX RT-HR with OVX Sed.

The OVX Sed presented significantly lower values of biomechanical variables compared to SHAM Sed $(P<0.05$, Fig 3). The comparison between SHAM Sed and SHAM RT demonstrated that RT induced significantly higher stiffness, fracture load and maximum load $(P<0.05)$. The same results were observed when comparing OVX RT with OVX Sed $(P<$ 0.05). RT associated with HR (OVX RT-HR) had significantly higher stiffness, fracture load and maximum load when compared to OVX RT and OVX Sed $(P<0.05)$.

Significantly higher MMP-2 activity (pro and active isoforms) in the following comparison: SHAM RT group was compared with SHAM Sed $(P<0.05$, Fig 4$)$, OVX RT to OVX Sed $(P<$ $0.05)$ and OVX RT-HR with OVX Sed $(P<0.05)$. On the other hand, only HR was able to promote higher MMP-2 activity in OVX HR compared to OVX Sed $(P<0.05)$. 
FIGURE 1: Physical analysis of the left tibia: A) bone density (mg/cm3), B) bone mineral content (mg), and C) area (cm2). Values are presented as mean \pm standard deviation of mean $(\mathrm{SDM}), \mathrm{P}<0.05$. *Statistical difference compared to SHAM Sed, \#Statistical difference compared to OVX Sed, and \&Statistical difference compared to OVX RT-HR.

$$
\text { SHAM } \square \text { OVX } \square \text { OVX + HR }
$$
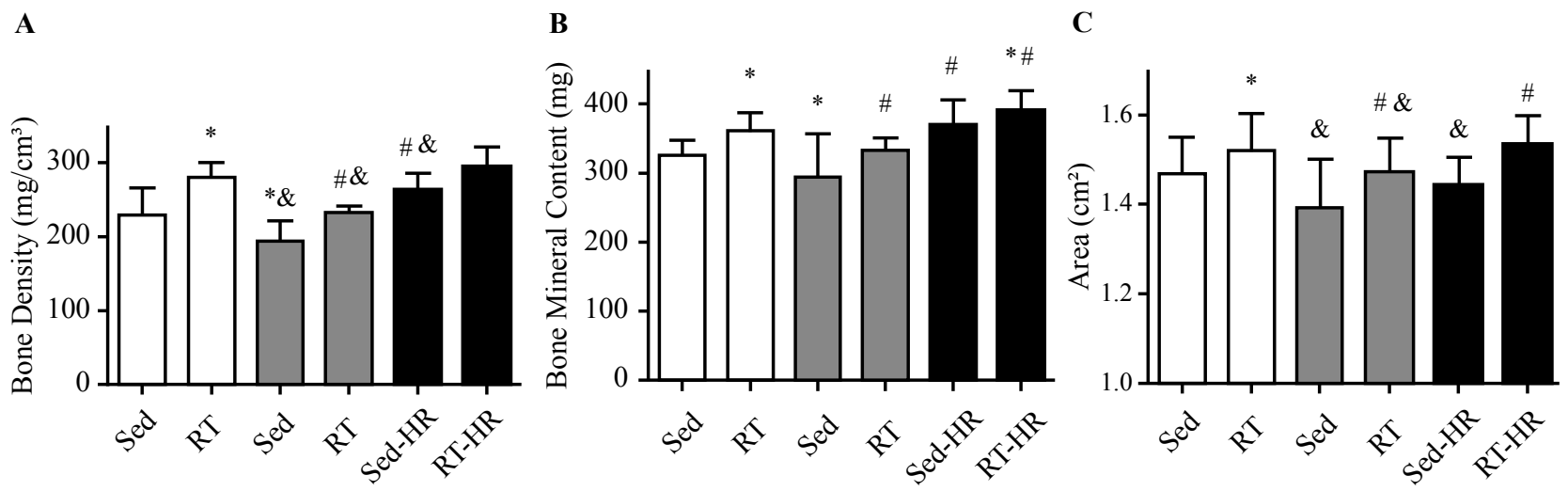

FIGURE 2: Calcium $\left(\mathrm{Ca}^{++}\right.$and phosphorus (P) analysis of the left tibia: A) calcium ( $\left.\mathrm{mg} \mathrm{Ca}{ }^{++} / \mathrm{mg} \mathrm{Bone}\right)$, B) phosphorus ( $\mathrm{gP} / \mathrm{g}$ Bone). Values are presented as mean \pm standard deviation of mean $(\mathrm{SDM}), \mathrm{P}<0.05$. *Statistical difference compared to SHAM Sed; \#Statistical difference to group OVX Sed.

$\mathbf{A}$



B



FIGURE 3: Biomechanical analysis of the left tibia: A) Stiffness (N/mm), B) fracture load (N), and C) maximum load (N). Values are presented as mean \pm standard deviation of mean $(\mathrm{SDM}), \mathrm{P}<0.05 . *$ Statistical difference compared to group SHAM Sed; \#Statistical difference compared to group OVX Sed.
SHAM
OVX
$\mathrm{OVX}+\mathrm{HR}$

$\mathbf{A}$

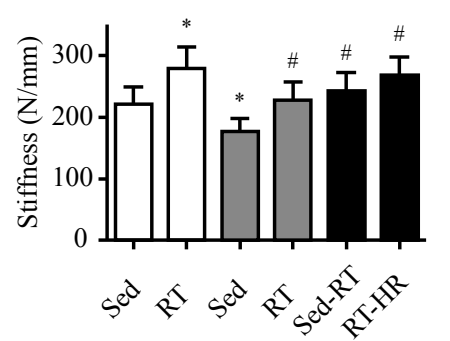

B



C




FIGURE 4: Effects of resistance training (RT), ovariectomy and hormone replacement (HR) on pro and active MMP-2 bands on the right tibia. Data are expressed as arbitrary units (AU). Values are presented as mean \pm standard deviation of mean (SDM), P $<0.05$. *Statistical difference compared to SHAM Sed, \#Statistical difference compared to OVX Sed, \$Statistical difference compared to OVX Sed-HR, and \&Statistical difference compared to all groups.


\section{Discussion}

The main results of this study were that ovariectomy has a negative effect in MMP-2 activity and biophysical and biomechanical properties of bone, while the RT was effective to improve these deleterious changes on the bone tissue of OVX rats. Ovariectomy contributed to increasing the body weight, and there were significant reductions in the BMC and BD in the OVX Sed group compared with SHAM Sed and SHAM RT groups.

The increase in body weight of ovariectomized animals was accompanied by reductions in the calcium and phosphorus concentrations and bone MMP-2 activity, demonstrating the relationship between ovarian hormones and bone biochemical 
markers. These biochemical changes reflect negatively on biomechanical analyzes (stiffness and strength), reducing the quantity and the quality of tissue. Interestingly, RT increased the concentrations of calcium, phosphorus and MMP-2 activity, which may contribute to greater strength and tissue remodeling. Still, RT and HR increased significantly the activity of MMP-2. Confirming our hypothesis, the MMP-2 activity in the RT, HR and RT-HR groups was greater compared to all other groups.

Furthermore, the absence of ovarian hormones promotes the reduction in the ability to repair bone tissue microfractures maintain the integrity of the mineral phase. This phase is composed of hydroxyapatite crystals and reflects the bone mineral content (BMC) and bone density (BD). In the study, the levels of calcium and bone phosphorus were higher in trained animals that underwent HR. The RT and HR are effective to promote the deposition of these minerals in bone tissue, contributing to higher levels of strength and toughness. Training and HR was able to increase the stiffness, strength and load of bone fracture. Several mechanisms that influence the activity of osteoblasts and osteoclasts, and interfere with the bone remodeling process may explain this finding.

Renal damage affects the metabolism of calcium and phosphorus, influencing the activity of osteoblasts and osteoclasts in the process of bone remodeling ${ }^{26}$. Estrogen promotes tubular reabsorption of calcium, and the rise in bone resorption at the lack of hormones could be accounted for, at least in part, by the effect of estrogen deficiency on the kidney. A rise in urinary calcium in the absence of ovarian hormones is the factor that contributes to the development of osteopenia ${ }^{5}$. On the other hand, it is known that mechanical stress produced by exercise training improves the bone mass ${ }^{27,28}$, mediated by the release of insulin-like growth factor-1 (IGF-1) by osteoblasts, which promotes the proliferation of these cells. The results of our study are corroborated by Pierce, Lee ${ }^{26}$, demonstrating that RT of moderate intensity promotes increases in BMC in rats ${ }^{1}$, Thus, the estrogen replacement has the capacity to increase bone formation concomitant with decreased bone resorption is due to the training load (body mass + training load) and higher concentrations of hormone, favoring greater mineral deposition ${ }^{29}$.

The markers of the extracellular matrix are also involved in the remodeling of the bone tissue. Isaksson, Tolvanen ${ }^{19}$ observed that the running exercise in rats for six months was capable of increase strength and toughness of the bone tissue increasing the mineral deposition and formation of the collagen network. Shiguemoto, Prestes ${ }^{3}$ reported that the training was effective to enhance the biomechanical capabilities of bones by increasing bone resorption.

The increased activity of MMPs is indicative of matrix degradation - a process necessary for tissue growth. The MMP-2 to its active form $(62 \mathrm{kD})$ preserves bone mass. The decrease in MMP-2 destroys the bone tissue, favoring osteoporosis ${ }^{7}$. Ovariectomy decreases the activity of MMP-2 and the production of collagen type I and III. Collagen type I is found abundantly, promoting elasticity and strength to the bone ${ }^{12}$. Therefore, change in collagen, as occurs in osteoporosis, may affect the mechanical property of the tissue, making it susceptible to fractures ${ }^{19}$.
The bone demineralization and the decrease of collagen are associated with the high rate of bone remodeling (negative bone balance), thereby promoting reduction in the biophysical and biomechanical properties of bones ${ }^{3}$.

Our results showed a marked reduction in MMP-2 activity and its isoforms, pro and active, in OVX Sed, when compared to the other groups. On the other hand, the training and hormone replacement was able to increase the activity of both forms of MMP-2. BMC, BD, stiffness, bone fracture resistance and MMP-2 activity reduced, decreasing bone mass. Thus, it can be noted that ovariectomy favors dramatic increases in bone turnover, followed by rapid loss of bone mass. Ramage, Nuki ${ }^{27}$ showed that mechanical stress, together with the signaling of pro inflammatory cytokines, stimulate bone chondrocytes in cartilage. Thus, we can state that the proposed resistance training is effective in reducing the damaging effects caused by ovariectomy on bone tissue.

Estrogen deficiency is related to the occurrence and progression of osteopenia and osteoporosis and regulated by a powerful cytokine TNF- $\alpha$, which is a primary mediator of bone resorption acting through the osteoprotegerin receptor (OPG) activator of the nuclear factor $\mathrm{kB}$ (RANK) system and inhibits a mesenchymal stem cell to become an osteoblast $\mathrm{t}^{29}$.

This activation depends on key factors such as runt-related transcription factor 2 (RUNX-2), bone morphogenetic proteins 2 , and transforming growth factor- $\beta$ (TGF- $\beta)^{12}$. Decreasing estrogen levels causes the release of TNF- $\alpha$ from immune cells, and then, TNF- $\alpha$ directly stimulates osteoclastic bone catabolism. Importantly, the lack of ovarian hormones in bone marrow might promote bone resorption because marrow adipocytes, much like fat cells elsewhere secrete inflammatory cytokines capable of recruiting osteoclasts ${ }^{12}$. Moreover, there is a complex interplay between estrogens and fat within the bone tissue $^{12}$. Evely, Bonomo ${ }^{28}$ exhibited that there was a marked fatty bone-marrow infiltration in rats following ovariectomy, proposing that estrogen must play an important role in regulating adipocyte recruitment.

The proposed training and HR in this study increase significantly the activity of MMP-2, and is indeed accompanied by increased $\mathrm{BMC}, \mathrm{BD}$, maximum rigidity and strength. These results have been observed in other studies with intact rats ${ }^{3}$, demonstrating that resistance training and high intensity exercise affect bone mass in intact rats. A limitation of the present study is the lack of bone collagen, pro-inflammatory cytokines and markers of osteoblast and osteoclast differentiation analysis, since, this has a significant function of promoting elasticity and strength to the bone.

In conclusion, we present evidences that ovariectomy imposes drastic and negative changes in MMP-2 activity, decreasing the biophysical and biomechanical properties of bone intrinsically mimicking the deleterious effects of menopause on bone remodeling. However, RT in our study was effective in preventing the deleterious changes on the bone tissue of OVX rats. When there was a joint RT with HR, these results were even more favorable to the health of the bone tissue. 


\section{References}

1. Yang JH, Kim JH, Lim DS, Oh KJ. Effect of combined sex hormone replacement on bone/cartilage turnover in a murine model of osteoarthritis. Clin Orthop Surg. 2012;4(3):234-41.

2. Abdallah BM, Kassem M. New factors controlling the balance between osteoblastogenesis and adipogenesis. Bone. 2012;50(2):540-5.

3. Shiguemoto GE, Prestes J, Leite RD, Pereira GB, Pontes CL, D'Avila FV, et al. Effects of resistance training on matrix metalloproteinase-2 activity and biomechanical and physical properties of bone in ovariectomized and intact rats. Scand J Med Sci Sports. 2012;22(5):607-17.

4. Sipos W, Pietschmann P, Rauner M, Kerschan-Schindl K, Patsch J. Pathophysiology of osteoporosis. Wien Med Wochenschr. 2009;159(9-10):230-4.

5. Nordin BE, Morris HA. The calcium deficiency model for osteoporosis. Nutr Rev. 1989;47(3):65-72.

6. Gala J, Diaz-Curiel M, de la Piedra C, Calero J. Short- and longterm effects of calcium and exercise on bone mineral density in ovariectomized rats. Br J Nutr. 2001;86(4):521-7.

7. Matsuo K, Nango N. [Osteocytic osteolysis : measurements of the volume of osteocytic lacunae]. Clin Calcium. 2012;22(5):677-83.

8. Chapurlat RD, Delmas PD. Bone microdamage: a clinical perspective. Osteoporos Int. 2009;20(8):1299-308.

9. Pereira GB, Prestes J, Leite RD, Magosso RF, Peixoto FS, Marqueti Rde C, et al. Effects of ovariectomy and resistance training on MMP-2 activity in rat calcaneal tendon. Connect Tissue Res. 2010;51(6):459-66.

10. Leite RD, Prestes J, Pereira GB, Shiguemoto GE, Perez SE. Menopause: highlighting the effects of resistance training. Int $\mathrm{J}$ Sports Med. 2010;31(11):761-7.

11. Marqueti RC, Prestes J, Stotzer US, Paschoal M, Leite RD, Perez SE, et al. MMP-2, jumping exercise and nandrolone in skeletal muscle. Int J Sports Med. 2008;29(7):559-63.

12. Cao JJ. Effects of obesity on bone metabolism. J Orthop Surg Res. 2011;6:30.

13. Heber D. An integrative view of obesity. Am J Clin Nutr. 2010;91(1):280S-3S.

14. Schett $\mathrm{G}$. Effects of inflammatory and anti-inflammatory cytokines on the bone. Eur J Clin Invest. 2011;41(12):1361-6.

15. Iwamoto J, Sato Y, Takeda T, Matsumoto H. Role of sport and exercise in the maintenance of female bone health. J Bone Miner Metab. 2009;27(5):530-7.

16. Simoes PA, Zamarioli A, Bloes P, Mazzocato FC, Pereira LH, Volpon JB, et al. Effect of treadmill exercise on lumbar vertebrae in ovariectomized rats: anthropometrical and mechanical analyses. Acta Bioeng Biomech. 2008;10(2):39-41.

17. de Oliveira ML, Bergamaschi CT, Silva OL, Nonaka KO, Wang CC, Carvalho AB, et al. Mechanical vibration preserves bone structure in rats treated with glucocorticoids. Bone. 2010;46(6):1516-21.

18. Falcai MJ, Zamarioli A, Okubo R, de Paula FJ, Volpon JB. The osteogenic effects of swimming, jumping, and vibration on the protection of bone quality from disuse bone loss. Scand J Med Sci Sports. 2015;25(3):390-7.

19. Isaksson H, Tolvanen V, Finnila MA, Iivarinen J, Tuukkanen J, Seppanen K, et al. Physical exercise improves properties of bone and its collagen network in growing and maturing mice. Calcif Tissue Int. 2009;85(3):247-56.

20. Souza MV, Leite RD, Souza Lino AD, Marqueti Rde C, Bernardes $\mathrm{CF}$, Araujo HS, et al. Resistance training improves body composition and increases matrix metalloproteinase 2 activity in biceps and gastrocnemius muscles of diet-induced obese rats. Clinics (Sao Paulo). 2014;69(4):265-70.

21. Kalu DN. The ovariectomized rat model of postmenopausal bone loss. Bone Miner. 1991;15(3):175-91.

22. Hornberger TA, Jr., Farrar RP. Physiological hypertrophy of the FHL muscle following 8 weeks of progressive resistance exercise in the rat. Can J Appl Physiol. 2004;29(1):16-31.

23. Leite RD, Prestes J, Bernardes CF, Shiguemoto GE, Pereira GB, Duarte JO, et al. Effects of ovariectomy and resistance training on lipid content in skeletal muscle, liver, and heart; fat depots; and lipid profile. Appl Physiol Nutr Metab. 2009;34(6):1079-86.

24. Ingberg E, Theodorsson A, Theodorsson E, Strom JO. Methods for long-term 17beta-estradiol administration to mice. Gen Comp Endocrinol. 2012;175(1):188-93.

25. Trebacz H, Zdunek A. Three-point bending and acoustic emission study of adult rat femora after immobilization and free remobilization. J Biomech. 2006;39(2):237-45.

26. Pierce RA, Lee LC, Ahles CP, Shdo SM, Jaque SV, Sumida KD. Different training volumes yield equivalent increases in BMD. Int J Sports Med. 2010;31(11):803-9.

27. Ramage L, Nuki G, Salter DM. Signalling cascades in mechanotransduction: cell-matrix interactions and mechanical loading. Scand J Med Sci Sports. 2009;19(4):457-69.

28. Evely RS, Bonomo A, Schneider HG, Moseley JM, Gallagher J, Martin TJ. Structural requirements for the action of parathyroid hormone-related protein (PTHrP) on bone resorption by isolated osteoclasts. J Bone Miner Res. 1991;6(1):85-93.

29. Devlin MJ. Estrogen, exercise, and the skeleton. Evol Anthropol. 2011;20(2):54-61.

\section{Acknowledgements}

The authors thank: Financial support provided by the Coordenação de Aperfeiçoamento de Pessoal de Nível Superior (CAPES) and the Fundação de Amparo à Pesquisa do Estado de São Paulo (FAPESP), Process: 2011/21607-5; Laboratory of Exercise Physiology - Federal University of São Carlos (São Carlos, Brazil).

\section{Corresponding author}

*Markus Vinicius Campos Souza

Federal University of Triângulo Mineiro, Department of Sport Sciences, Uberaba/ MG, Brazil. Av. Getúlio guaritá, 159, Uberaba,Minas Gerais, Brazil.

Email: markusviniciuscampos@gmail.com

Manuscript received on July 27, 2017

Manuscript accepted on October 4, 2017

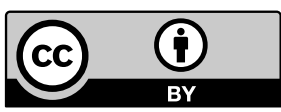

Motriz. The Journal of Physical Education. UNESP. Rio Claro, SP, Brazil - eISSN: 1980-6574 - under a license Creative Commons - Version 3.0 